\title{
Modification of Black Liquor and Naphthalene Formaldehyde Superplasticizer and Research on Concrete Performance
}

\author{
Tailong Zhang ${ }^{1, a}$, Jianming Gao ${ }^{2, b}$, Bing Qi ${ }^{1, c}$ and Yanling Liu ${ }^{1, d}$ \\ ${ }^{1}$ Department of Materials Science \& Engineering, Southeast University, Nanjing 211189, China \\ 2 Jiangsu Key Laboratory of Construction Materials, Southeast University, Nanjing 211189, China \\ azhangtailong1976@163.com, bJmgao@seu.edu.cn, cqibing5@126.com, dyanliu@126.com
}

\begin{abstract}
Keywords: Black liquor; Naphthalene Formaldehyde Superplasticizer; Chemical modification; Concrete; Infrared spectrum analysis

Abstract. A new kind of Naphthalene Formaldehyde Superplasticizer (M20N80) was prepared through the modification of black liquor and Naphthalene Formaldehyde Superplasticizer (N) through an $\mathrm{Fe} 2+-\mathrm{H} 2 \mathrm{O} 2$ reaction system. The synthesis process and synthesis mechanism of M20N80 was introduced. Infrared spectrum analysis (FT-IR) was used to investigate the changes in functional groups in M20N80. In comparison with $\mathrm{N}$ and LM20N80, the influences of M20N80 on the properties of concrete were studied. The results indicate that M20N80 had a better water reduction rate in concrete than LM20N80 and was close to $\mathrm{N}$ under the same conditions. Furthermore, $\mathrm{M} 20 \mathrm{~N} 80$ and $\mathrm{N}$ had almost the same effect on compressive strength development of concrete. Finally, M20N80 appeared to be more effective in improving the pore structure of concrete.
\end{abstract}

\section{Introduction}

Black liquor is a by-product of papermaking industry. The amount of black liquor is enormous and the output is about 60 million tons every year. Most of them are used as fuel causing huge energy waste and serious environmental pollution[1]. In order to make full use of these renewable resources, people began to make lignosulfonate as concrete admixture from black liquor since the 1930s[2-3]. Because of particular structure with specific functional groups such as -SO32-,-OH-,-O-,etc., lignosulfonate has high reactivity[4] and was wildly used for producing water reducing admixtures. However, because of poor water reducing rate and obvious retarding effect, lignosulfates cannot completely meet the requirements of construction of modern concrete. Therefore, many modification studies has been carried out in order to improve the performance of lignosulfonate[5].

In this paper, the mixture of black liquor and $\mathrm{S}($ black liquor : $\mathrm{N}=1: 4, \mathrm{w} / \mathrm{w}$ ) was modified by $\mathrm{Fe} 2+-\mathrm{H} 2 \mathrm{O} 2$ reaction system, which was characterized by FT-IR to investigate the variation of functional groups. The process of modification to black liquor and $\mathrm{N}$ was introduced. In comparison with $\mathrm{N}$ and LM20N80, the water reducing effect ofM20N80 and its influences on compressive strength and pore structure of concrete were studied.

\section{Experimental}

Materials.Black liquor and Naphthalene Formaldehyde Superplasticizer (N) were supplied by Jiangsu TMS Concrete Admixture Co., Ltd. in Jiangsu province, PR China. Black liquor was obtained from sulfate pulping of wheat stalk. Its lignin and ash content were determined to be $69.3 \%$ and $19.5 \%$ according to TAPPI T222 and TAPPI T211, respectively, and the rest component was degradative carbohydrates. Table 1 presents the uniformity properties of black liquor and N. The molecular structure of $\mathrm{N}$ is shown in Fig. 1. Formaldehyde, ferrous sulfate and hydrogen peroxide (analytical purity) were purchased from Huadong Chemicals Co., Ltd. in Jiangsu province, PR China. Portland cement PII42.5R was supplied by Nanjing Jiangnan Cement Co., Ltd. in Anhui province, PR China. The chemical compositions and properties of the cement are shown in Table 2. 
Table 1.Properties of Black Liquor and N

\begin{tabular}{|c|c|c|}
\hline Name & $\mathrm{pH}$ Value & Solid-containing Content \\
\hline Black liquor & 12.5 & $46 \%$ \\
\hline $\mathrm{N}$ & 4.0 & $40 \%$ \\
\hline
\end{tabular}

Table 2.Chemical Composition and Physical Properties of Cement

\begin{tabular}{|c|c|c|c|c|c|c|}
\hline \multirow[t]{2}{*}{$\begin{array}{l}\text { Specific } \\
\text { Surface }\end{array}$} & Chemical Composition (\%) & \multirow{2}{*}{$\begin{array}{c}\text { Normal } \\
\text { Consistency (\%) }\end{array}$} & $\begin{array}{c}\text { Setting } \\
\text { Time (min) }\end{array}$ & \multirow[t]{2}{*}{ Stability } & $\begin{array}{c}\text { Flexural } \\
\text { Strength } \\
(\mathrm{MPa})\end{array}$ & $\begin{array}{c}\text { Compression } \\
\text { Strength } \\
(\mathrm{MPa})\end{array}$ \\
\hline & $\begin{array}{c}\mathrm{SiO} 2 \mathrm{Al} 2 \mathrm{O} 3 \mathrm{CaO} \mathrm{MgO} \\
\mathrm{SO}_{3} \mathrm{Fe}_{2} \mathrm{O}_{3} \text { Loss }\end{array}$ & & $\begin{array}{c}\text { Initial } \\
\text { Final }\end{array}$ & & $\begin{array}{c}3 \mathrm{~d} \\
28 \mathrm{~d}\end{array}$ & $\begin{array}{c}3 \mathrm{~d} \\
28 \mathrm{~d}\end{array}$ \\
\hline 370 & $\begin{array}{ccccc}20.6 & 5.03 & 65.06 & 0.55 & 2.24 \\
& 4.38 & 1.30 & \end{array}$ & 29 & $140 \quad 195$ & Qualified & $\begin{array}{l}5.5 \\
8.5\end{array}$ & $\begin{array}{l}27.5 \\
55.0\end{array}$ \\
\hline
\end{tabular}

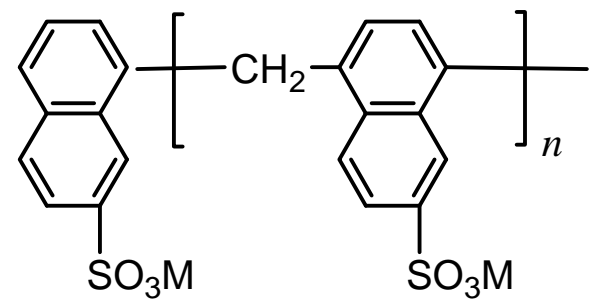

Fig. 1. Molecular structure of $\mathrm{N}$

\section{Methods}

Synthesis process.First, $20 \mathrm{~g}$ of black liquor and $5 \mathrm{~g}$ of formaldehyde were placed in a reaction vessel equipped with stirrer, thermometer, and condenser. The solution was stirred (stirring velocity of 150 $\mathrm{r} / \mathrm{min}$ ) and heated to $100^{\circ} \mathrm{C}$, keep the temperature for $2 \mathrm{~h}$. Then, $80 \mathrm{~g}$ of $\mathrm{N}, 0.06 \mathrm{~g}$ of ferrous sulfate, 0.5 $\mathrm{g}$ of hydrogen peroxide were added at a constant velocity under stirring to start the reaction, which was carried out at $95^{\circ} \mathrm{C}$ for $3 \mathrm{~h}$. The $\mathrm{pH}$ value was adjusted by adding $35 \mathrm{wt} . \% \mathrm{NaOH}$ aqueous solution. The reaction mixture was then allowed to cool to room temperature. Finally, the modified M20N80 was obtained with a solid content of 32.26\% and a pH value of between 8 and 9. The synthesis flow chart of M20N80 is illustrated in Fig. 2. Meanwhile, for comparative study, LM20N80 was also prepared by mixing $20 \mathrm{~g}$ of black liquor and $80 \mathrm{~g}$ of $\mathrm{N}$ directly at room temperature. The $\mathrm{pH}$ value of LM20N80 was adjusted to be the same as that of M20N80.The synthesis mechanism of M20N80 is shown in Fig.3.

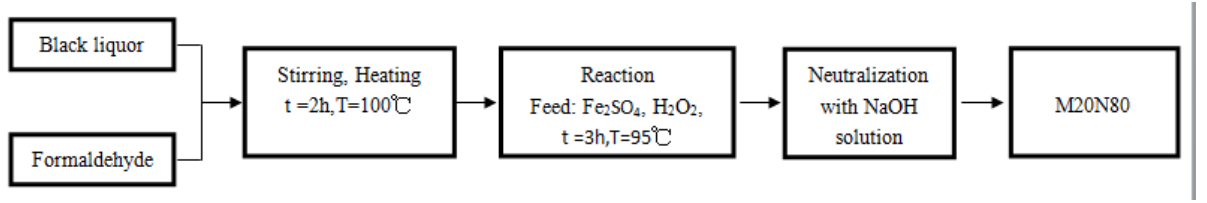

Fig.2. Modification scheme of black liquor and S 


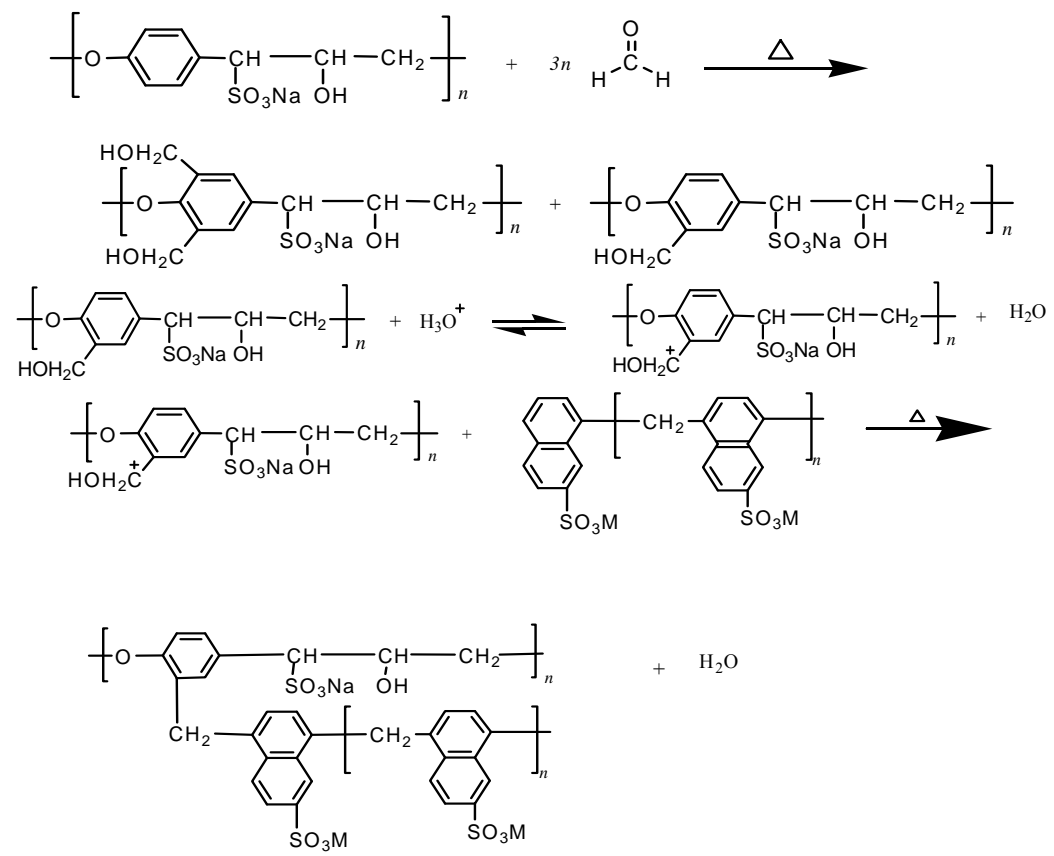

Fig.3.Synthesis mechanism of M20N80

Fourier transform infrared spectroscopy (FT-IR). Fourier transform infrared spectroscopy was performed with a Bio-Rad FTS 6000 FTIR(USA)using KBr pellet techniques to measure the energy absorption of the ancient samples. Here, $3 \mathrm{mg}$ of finely-ground $(<80-\mathrm{m})$ specimen powder was homogenously ground with $300 \mathrm{mg}$ of $\mathrm{KBr}$ powder until the mixture had the consistency of fine flour, and was then pressed into a thin 15-mm-diameter disc.

Water-reducing rate(WR).The water-reducing rate was tested according to the Chinese standard GB/T8076 (2008).

Compressive strength. The compressive strengths of the specimens cured for 3,7, and 28 days were measured using a closed-loop servo-hydraulically-controlled materials testing machine (MTS 810, USA) following the ASTM C270-12a (2012) standard.

Mercury intrusion porosimetry (MIP). The porosity and pore size distribution of concrete at different ages were determined using a mercury intrusion porosimeter (AutoPoreIV9500;Micromeritics,USA) capable of generating pressure in the range of subambient to 33000psi. The pore radius calculation was done using the Washburn's equation(Kumar and Bhattacharjee 2003), i.e., $r=-2 * \gamma^{*} \cos \theta / \mathrm{P}$, where $\mathrm{r}$ is the pore entry radius in which mercury is being intruded, $\gamma$ is surface tension, and $\theta$ and $\mathrm{P}$ are the contact angles of mercury with solid and applied pressure, respectively.

\section{Results and discussion}

FT-IR Characterization.Figures 4 and 5 represent the infrared spectrum of LM20N80 and M20N80, respectively.As shown in Fig. 4, the main specific absorption peaks of LM20N80 appeared at $3404.60 \mathrm{~cm}^{-1}, 1591.74 \mathrm{~cm}^{-1}, 1423.10 \mathrm{~cm}^{-1}, 1126.26 \mathrm{~cm}^{-1}, 957.63 \mathrm{~cm}^{-1}, 779.52 \mathrm{~cm}^{-1}$ which were assignedtothe $\mathrm{O}-\mathrm{H}$ stretching vibration, stretching vibration in benzene ring group,- $\mathrm{CH}_{2} \mathrm{symmetric}$ stretching vibration, $\mathrm{S}=\mathrm{O}$ asymmetric stretching vibration in sulfonic group, $\mathrm{O}-\mathrm{H}$ stretching vibration, out-plane flexural vibration in the benzene.As shown in Fig. 5, the main specific absorption peaks of M20N80 appeared at3408.04 $\mathrm{cm}^{-1}, 1564.21 \mathrm{~cm}^{-1}, 1432.57 \mathrm{~cm}^{-1}, 1183.05 \mathrm{~cm}^{-1}, 1099.59$ $\mathrm{cm}^{-1}, 1016.13 \mathrm{~cm}^{-1}, 885.35 \mathrm{~cm}^{-1}$, which were assigned tothe $\mathrm{O}-\mathrm{H}$ stretching vibration,stretching vibration in benzene ring group, $-\mathrm{CH}_{2}$ symmetric stretching vibration, $\mathrm{S}=\mathrm{O}$ asymmetric stretching vibration in sulfonic group, $\mathrm{O}-\mathrm{H}$ stretching vibration, out-plane flexural vibration in the benzene, 
respectively. The above analysis showed that the absorption peaks were changed after oxidation. It was implied thatgraft reaction between lignin and $\mathrm{N}$ had happened through free radical polymerization.

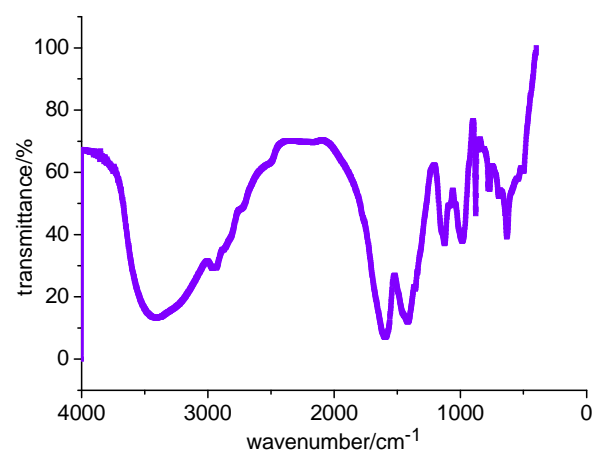

Fig. 4. Infrared spectrum of LM20N80

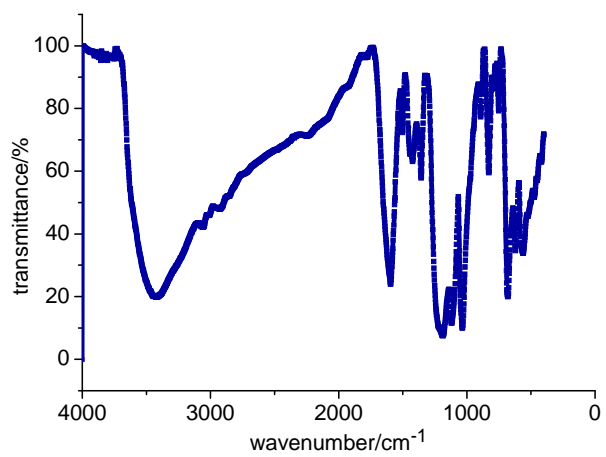

Fig. 5. Infrared spectrum of M20N80

Water-reducing Rate.Fig. 6 shows variations in the water-reducing rates of N, LM20N80, and M20N80 with the same dosage of $1.5 \%$. The water-reducing rate of concrete with S, LM20N80, and M20N80 was $18 \%, 16.2 \%$, and $19.7 \%$, respectively. This means that the water-reducing rate of M20N80 was obviously better than that of LM20N80, even slightly better than that of N. The results indicate that chemical modification effectively improved the water-reducing rate of M20N80 which was comparable to that of the pureN.

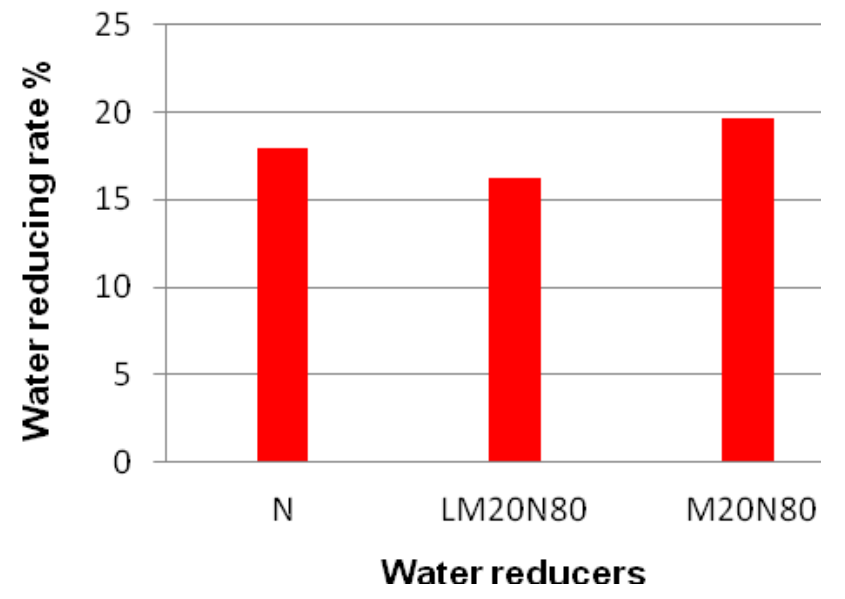

Fig. 6. Water-reducing rate of concrete with different waterreducers

Compressive Strength. Table 3 shows variations in the compressive strength of concrete cured for 3 , 7, and 28 days. Compared with the reference sample $(\mathrm{K})$, the compressive strength of concrete with the same dosages of N, LM20N80, and M20N80 were obtained. According to the results, the compressive strength of concrete with the water-reducing agent was higher than that of the blank concrete at every curing age. It can be seen in Table 3 that the compressive strength ratios of concrete with N, LM20N80, and M20N80 were 138\%, 122\%, and 132\%, respectively, after curing for 3 days. According to the results for 28 days of curing, the compressive strength ratios of concrete with $\mathrm{S}$, LM20N80, and M20N80 were 133\%, 114\%, and 130\%, respectively. This revealed that LM20N80 delayed the hydration of cement in comparison with N and M20N80.The M20N80 and N had almost the same effect on concrete compressive strength development. 
Table 3Effect of water reducer dosages on the compressive strength of concrete

\begin{tabular}{ccccc}
\hline \multirow{2}{*}{ Name } & $\begin{array}{c}\text { Dosage } \\
(\mathrm{C} \%)\end{array}$ & \multicolumn{2}{c}{ Compressive strength $(\mathrm{MPa}) /$ Compressive strength ratio } \\
\cline { 3 - 4 } $\mathrm{K}$ & 0 & $3 \mathrm{~d}$ & $7 \mathrm{~d}$ & $28 \mathrm{~d}$ \\
$\mathrm{~N}$ & $1.5 \%$ & $19.9 / 100$ & $28.5 / 100$ & $36.4 / 100$ \\
LM20N80 & $1.5 \%$ & $27.5 / 138$ & $40.2 / 141$ & $48.5 / 133$ \\
M20N80 & $1.5 \%$ & $24.2 / 122$ & $36.1 / 127$ & $41.6 / 114$ \\
\end{tabular}

Pore Structure of Concrete.Table 4shows variations in the pore structure of concrete with different water-reducing agents. The most probable pore sizes of concrete with the same contents of $\mathrm{N}$, LM20N80, and M20N80 were $47.87 \mathrm{~nm}, 61.89 \mathrm{~nm}$, and $50.20 \mathrm{~nm}$, respectively, while the most probable pore size of blank concrete $(\mathrm{K})$ was $77.25 \mathrm{~nm}$, which was shown in Fig. 7. The pore structure of concrete was improved when the water-reducing agent was used. According to the total porosity results in Table 4, the concrete with M20N80 had the smallest total porosity with the same water-reducing agent content. In addition, with the increase of M20N80 dosages from $0.9 \%$ to $1.8 \%$, the total porosity of concrete decreased from $16.91 \%$ to $13.77 \%$, and the most probable pore size of concrete decreased from $73.34 \mathrm{~nm}$ to $46.33 \mathrm{~nm}$, as shown in Fig.8. These results imply that M20N80 performed better for improving the pore structure of concrete. This may be attributed to the fact that M20N80 improved the dispersion of cement and the growth of hydration products because of its excellent water-reducing ability and certain retarding talent.

Table 4. Influence of Water-reducing Agent on Pore Size Distribution

\begin{tabular}{|c|c|c|c|c|c|c|c|}
\hline \multirow{2}{*}{ Name } & \multirow{2}{*}{ Dosage } & \multicolumn{4}{|c|}{ Pore Size Distribution /\% } & \multirow{2}{*}{$\begin{array}{l}\text { Void Volume } \\
\left(\mathrm{x} 10^{-4} \mathrm{ml} / \mathrm{g}\right)\end{array}$} & \multirow{2}{*}{ Total Porosity $/ \%$} \\
\hline & & $0 \sim 20 \mathrm{~nm}$ & $20 \sim 100 \mathrm{~nm}$ & $100 \sim 200 \mathrm{~nm}$ & $>200 \mathrm{~nm}$ & & \\
\hline $\mathrm{K}$ & - & 24.4 & 25.91 & 8.93 & 40.76 & 850.95 & 17.2396 \\
\hline $\mathrm{N}$ & $1.5 \%$ & 28.21 & 32.79 & 6.18 & 32.82 & 680.86 & 14.1902 \\
\hline \multirow[t]{2}{*}{ LM20N80 } & $1.5 \%$ & 26.46 & 30.92 & 8.07 & 34.55 & 753.83 & 15.3004 \\
\hline & $0.9 \%$ & 23.65 & 31.4 & 8.95 & 36 & 881.22 & 16.9056 \\
\hline \multirow{3}{*}{ M20N80 } & $1.2 \%$ & 25.63 & 32.34 & 7.25 & 34.78 & 735.47 & 14.9753 \\
\hline & $1.5 \%$ & 27.68 & 35.22 & 4.58 & 32.52 & 675.58 & 13.7746 \\
\hline & $1.8 \%$ & 26.69 & 39.51 & 5.51 & 28.29 & 672.97 & 13.7680 \\
\hline
\end{tabular}

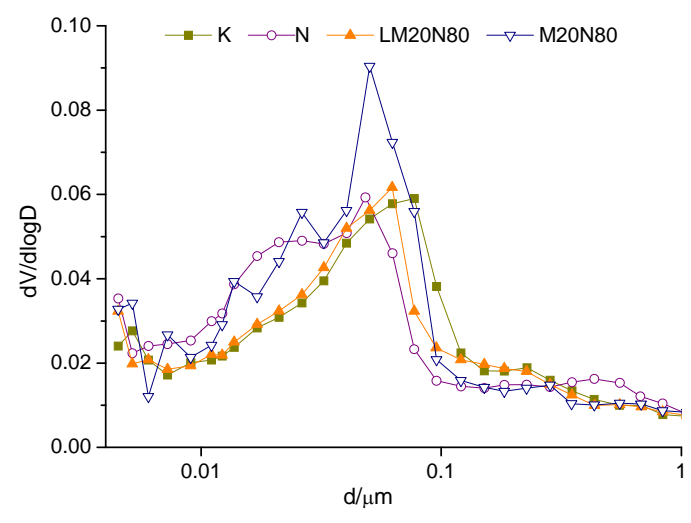

Fig. 7. Effect of water-reducing agent amount on pore size distribution of concrete

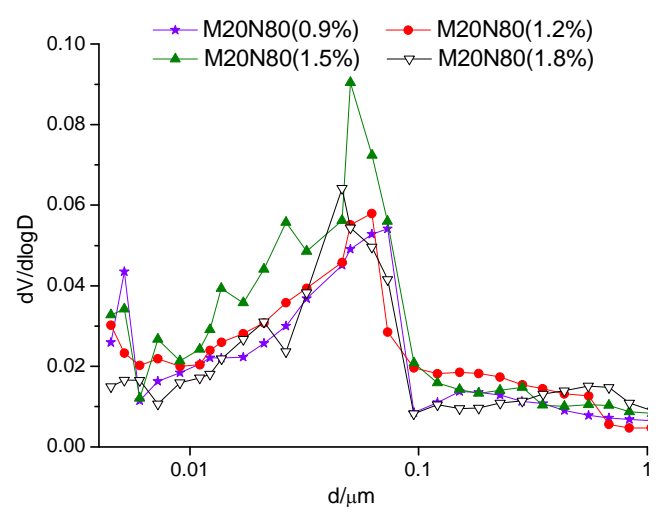

Fig. 8. Effect of M20N80 dosage on pore size distribution of concrete 


\section{Conclusions}

The results of infrared spectra analysis showed that after chemical modification with an $\mathrm{Fe}^{2+}-\mathrm{H}_{2} \mathrm{O}_{2}$ reaction system, M20N80had a different molecular structure. The product obtained was a new type of water-reducing agent, which had better water-reducing ability than LM20N80 and pure N.

Compared with concrete treated with LM20N80, the concrete treated with M20N80 after curing for $3 \mathrm{~d}$ and $28 \mathrm{~d}$ had higher compressive strength, which was comparable to the pure $\mathrm{N}$. In addition, M20N80 had no negative effect on the long-term strength of concrete.

Because of chemical modification, M20N80 showed good performance in water-reducing and retarding effects. Compared with LM20N80 and N, concrete mixed with M20N80 had better pore size distribution and smaller total porosity.

\section{References}

[1] D.Z. Ye, J. Li, C. Ma: Inter. J. Biolog. Macromole. Vol. 43-48 (2014), p. 63

[2] D.Y. Chang, Chan, Y.N. Sammy: Mag. Concr. Res. Vol. 113-118 (1995), p. 47

[3] A. Kamoun, A. Jelidi, M. Chaabouni: Cem. Concr. Res. Vol. 995-1003 (2003), p. 33

[4] T. Malutan, R. Nicu, V.I. Popa: BioResour. Vol. 13-20 (2008), p. 3

[5] G. Yu, B. Li, H.S. Wang, C. Liu, X.D. Mu: Mag. Concr. Res. Vol. 1055-1063 (2013), p. 8 